\title{
Performance of Selected Native Ground Cover Species Under Induced Drought Conditions
}

\author{
M. S. N. Fernando and K. Yakandawala\# \\ Department of Horticulture and Landscape Gardening, \\ Faculty of Agriculture and Plantation Management, \\ Wayamba University of Sri Lanka, Makandura, Gonawila (NWP) \\ "Corresponding Author: \\ E-mail: yakandawalakapila@gmail.com
}

\begin{abstract}
Research related to water stress is becoming increasingly important as the changing climatic scenario is increasing aridity in many parts of the world. In this context, maintaining an acceptable landscape quality using less water has become a challenge. Ground covers are widely used in landscapes to fill spaces hence understanding how water stress affects ground covers is essential for selecting species that can sustain drought. Hence, the objective of this study was to determine the response of three native ground cover species Cynodon dactylon, Desmodium triflorum and Cyrtococcum trigonum for deficit irrigation and to identify the maximally acceptable irrigation deficit at which acceptable landscape quality could be maintained out of these species. A pot experiment was conducted to evaluate the growth performance and visual quality of the three ground cover species under three different water deficit levels $(75 \%, 65 \%$ and $55 \%$ field capacity) and under $100 \%$ field capacity (control). Each treatment consisted of 25 replicates and pots were arranged in Completely Randomized Design. Growth parameters and lawn quality was determined and the quantitative data was analyzed with SAS statistical package and lawn quality was analyzed with non-parametric methods. Induced drought conditions had a significant inhibitory effect on growth parameters and the overall lawn quality of studied species. In all three species shoot and root, fresh and dry weights were significantly reduced with induced drought. However, in $C$. dactylon, compared to $75 \%$ and $65 \%$ field capacity levels, at $55 \%$ field capacity level fresh and dry weights of shoots and roots were not significantly reduced. Similar observations were recorded with D. triflorum except for shoot fresh weight. In C. dactylon and D. triflorum, overall appearance is reduced after $65 \%$ field capacity level where as in C. trigonum, it was severely affected after $100 \%$ field capacity level. Hence $65 \%$ field capacity level can be considered as the acceptable irrigation deficit for $C$. dactylon and D. triflorum at which acceptable quality could be maintained. Compared to the other two species, deficit irrigation is not recommended for $C$. trigonum as it could reduce the visual quality.
\end{abstract}

KEYWORDS: Deficit irrigation, Ground cover, Growth parameters, Visual quality 


\section{Introduction}

Drought is one of the most serious environmental hazards that the world is facing at present. It can be defined in climatic terms to be a continuous interval of time during which the actual moisture supply at a given place is consistently less than normal (Riaz et al., 2010). According to UNEP (1992), about $47 \%$ of the surface of the earth can be classified as dry lands where average rainfall is less than the potential moisture losses through evaporation and transpiration. Hence, moisture is scarce for all or part of the year (Mortimore, 2009). Observations and model simulations indicate that ongoing global warming will cause increased droughts in dry areas and also an expansion of dry areas (Milesi et al., 2010; Overpeck and Udall, 2010). Droughts result in a water shortage condition that seriously interferes with plant activity (Riaz et al., 2010). Research related to water stress is becoming increasingly important because the changing climatic scenario is increasing aridity in many areas of the globe. It is now known that the extent of drought tolerance varies from species to species in almost all plant species (Lin et al., 2006).

Due to the shortage of water supply, water restrictions for landscaped areas have become common place in many countries around the world. Consequently, landscape managers are increasingly faced with the challenge of maintaining acceptable landscape quality using less water. Understanding the minimal irrigation requirements and extent of water stress that a particular plant species can tolerate while exhibiting acceptable quality is therefore highly valuable information for landscape managers (Wherley, 2011). Ground cover plants play an important role in urban landscapes; of which, turf grass is a key component. In Southern California, USA, recent estimates have suggested $41 \%$ of urbanized lands to be covered with turf grass (Nichols et al., 2012).

Grasses are the most important ground cover plants in the world (Fu et al., 2005). Researchers have found that grasses require water in amounts less than their evapotranspiration (ET) to maintain acceptable visual quality (Fry and Butler, 1989; $\mathrm{Fu}$ et al., 2004). Hence, deficit irrigation approaches has been practiced in grass management in various parts of the world in view of conservation of water (Qian and Engelke, 1999a; Fu et al., 2005; Bahrani et al., 2010). The Deficit irrigation is defined as supplying water in amounts less than actual ET measured under wellwatered conditions and has become an increasingly popular conservation technique in turf grass maintenance (Fry and Butler, 1989; Qian and Engelke, 1999b). Deficit irrigation in the transition zone of the United States is often practiced on tall fescue, a turf grass that is popular in the transition zone of the United States as a result of its heat tolerance and ability to avoid drought with deep rooting (Fu et al., 2007).

Irrigation deficits can be achieved by lengthening periods between irrigations or applying water more frequently at levels less than actual ET (Fu et al., 2007). As water conservation has becomes an important issue, interest is increasing in identifying ground covers that require less water. Particularly, lawn grass researchers have put a significant effort into developing and evaluating turf species that have good drought resistance (Fry and Butler, 1989). As grass systems are 
perhaps uniquely adapted for deficit irrigation because reductions in shoot growth are perceived to be beneficial, as long as visual and functional quality are not significantly sacrificed (Wherley, 2011). Drought tolerance, particularly in grasses is associated closely with their morphological and physiological traits (Bahrani et al., 2010). Hence, understanding how moisture stress affects ground covers is essential for selecting species that can sustain during drought periods, particularly in urban areas.

Urban areas are popularly planted with native and exotic plant species, of which, native plants are well adapted to low and variable precipitation. Hence, under these conditions native plants perform well compared to exotics. Therefore, understanding the minimal irrigation requirements and extent of water stress that a particular grass species can tolerate while exhibiting acceptable quality is therefore highly valuable for landscape managers. The objective of this study was to determine the response of three popular native ground cover species viz. Cynodon dactylon L.Pers., Desmodium triflorum L. (DC.) and Cyrtococcum trigonum (Retz.) A. Camus for deficit irrigation and to identify the maximally acceptable irrigation deficit at which acceptable landscape quality could be maintained out of these species.

\section{Materials and Methods}

The study was carried out at the faculty of Agriculture and Plantation Management, Wayamba University of Sri Lanka, Makandura (Low Country Intermediate zone $\mathrm{IL}_{1 \mathrm{a}}$ ) from January to December 2013 under a rain shelter to prevent rainfall on experimental pots.

Three ground cover species viz., Cynodon dactylon (Burmuda grass), Desmodium triflorum (Three-flower beggarweed) and Cyrtococcum trigonum were collected from the wild areas of the premises of the Wayamba University of Sri Lanka and runners were planted in black polyethylene bags $(12 \mathrm{~cm}$ diameter $\times 20 \mathrm{~cm}$ depth) containing $1.5 \mathrm{~kg}$ of media (top soil: sand 9: 2). Plants were allowed to establish for 50 days under the rain shelter and supplemented with a foliar fertilizer prior to water deficit experiments. Before initiation of the water deficit studies, plants were clipped at $12 \mathrm{~cm}$ diameter of coverage to maintain uniform plant size and all the pots were fully saturated with water. During the experiment, water stress was applied on the basis of soil field capacity by maintaining the calculated level of moisture percentage as given in Nudrat et al., (2008). Three water deficit treatments (75\%, 65\% and 55\% field capacity) along with $100 \%$ field capacity (control) were applied (Table 1). The method described by Somasegaran and Heben (1985) was used to determine percent soil moisture that approximates field capacity.

\section{The Experimental Design}

Pots were arranged in Completely Randomized Design (CRD) and three water deficit treatments along with $100 \%$ field capacity were used at four days intervals. Each treatment consisted of 25 replicates. 
Table 1. Details of treatment combinations used in the experiment

\begin{tabular}{ccc}
\hline Treatment & Ground cover species & Field capacity \\
\hline $\mathrm{T}_{1}$ & Cynodon dactylon & $100 \%$ \\
$\mathrm{~T}_{2}$ & Cynodon dactylon & $75 \%$ \\
$\mathrm{~T}_{3}$ & Cynodon dactylon & $65 \%$ \\
$\mathrm{~T}_{4}$ & Cynodon dactylon & $55 \%$ \\
$\mathrm{~T}_{5}$ & Desmodium triflorum & $100 \%$ \\
$\mathrm{~T}_{6}$ & Desmodium triflorum & $75 \%$ \\
$\mathrm{~T}_{7}$ & Desmodium triflorum & $65 \%$ \\
$\mathrm{~T}_{8}$ & Desmodium triflorum & $55 \%$ \\
$\mathrm{~T}_{9}$ & Cyrtococcum trigonum & $100 \%$ \\
$\mathrm{~T}_{10}$ & Cyrtococcum trigonum & $75 \%$ \\
$\mathrm{~T}_{11}$ & Cyrtococcum trigonum & $65 \%$ \\
$\mathrm{~T}_{12}$ & Cyrtococcum trigonum & $55 \%$ \\
\hline
\end{tabular}

\section{Data Recording}

Growth parameters including fresh and dry weights (oven dried at $80^{\circ} \mathrm{C}$ for 48 hours) of shoots and roots $(\mathrm{g})$, shoot and root length $(\mathrm{cm})$, and lawn quality were recorded. Lawn quality was determined based on colour, leaf coverage and overall appearance by conducting a survey consisting with 50 respondents.

\section{Data Analysis}

The quantitative data was analyzed with SAS statistical package and lawn quality was analyzed with non-parametric methods (Friedman test).

\section{Results}

\section{Shoot Growth Parameters}

The present study indicates that, induced drought conditions had a significant inhibitory effect on shoot growth parameters. Shoot fresh weight of all the three ground cover species recorded significantly high fresh weights at $100 \%$ field capacity (Table 2) while in $C$. dactylon, shoot fresh weights were not significantly different among other field capacity levels. However, in D. triflorum and $C$. trigonum shoot fresh weight was significantly reduced with induced drought conditions. 
Table 2. Shoot fresh weight (g) of ground cover species at different field capacity levels

\begin{tabular}{cccc}
\hline \multirow{2}{*}{ Field capacity \% } & \multicolumn{3}{c}{ Shoot fresh weight $(\mathrm{g})$} \\
\cline { 2 - 4 } & $\boldsymbol{C}$. dactylon & D. triflorum & C. trigonum \\
\hline 100 & $10.480^{\mathrm{a}} \pm 1.532$ & $9.228^{\mathrm{a}} \pm 2.932$ & $8.092^{\mathrm{a}} \pm 2.032$ \\
75 & $8.100^{\mathrm{b}} \pm 0.992$ & $6.492^{\mathrm{b}} \pm 1.630$ & $5.948^{\mathrm{b}} \pm 1.332$ \\
65 & $8.376^{\mathrm{b}} \pm 1.332$ & $5.006^{\mathrm{bc}} \pm 1.332$ & $4.908^{\mathrm{bc}} \pm 1.655$ \\
55 & $8.224^{\mathrm{b}} \pm 1.332$ & $4.876^{\mathrm{c}} \pm 0.732$ & $3.908^{\mathrm{c}} \pm 0.032$ \\
\hline
\end{tabular}

Means in a column with the same letters are not significantly different at the 0.05 probability level.

Shoot dry weight of all the three ground cover species recorded significantly high values at $100 \%$ field capacity compared to other field capacity levels (Table 3 ). However, $C$. dactylon recorded a significantly high shoot dry weight compared to other two species at $100 \%$ field capacity level. In all the three species, shoot dry weights were not significantly different among other field capacity levels.

Table 3. Shoot dry weight (g) of ground cover species at different field capacity levels

\begin{tabular}{cccc}
\hline \multirow{2}{*}{ Field capacity \% } & \multicolumn{3}{c}{ Shoot dry weight $(\mathrm{g})$} \\
\cline { 2 - 4 } & C. dactylon & D. triflorum & C. trigonum \\
\hline 100 & $5.208^{\mathrm{a}} \pm 1.002$ & $3.204^{\mathrm{b}} \pm 1.001$ & $3.720^{\mathrm{b}} \pm 0.902$ \\
75 & $3.720^{\mathrm{b}} \pm 1.030$ & $2.088^{\mathrm{c}} \pm 0.899$ & $2.056^{\mathrm{c}} \pm 0.998$ \\
65 & $3.740^{\mathrm{b}} \pm 0.702$ & $2.152^{\mathrm{c}} \pm 0.652$ & $1.804^{\mathrm{c}} \pm 0.600$ \\
55 & $3.228^{\mathrm{b}} \pm 0.692$ & $1.832^{\mathrm{c}} \pm 0.092$ & $1.544^{\mathrm{c}} \pm 0.332$ \\
\hline
\end{tabular}

Means in a column with the same letters are not significantly different at the 0.05 probability level.

The effect of induced drought conditions on shoot length was found to be not significant in $C$. dactylon and $D$. triflorum (Table 4). However, in C. trigonum a significant reduction in shoot length was observed between $100 \%$ and $65 \%$ and 55 $\%$ field capacity levels. 
Table 4. Shoot length $(\mathrm{cm})$ of ground cover species at different field capacity levels

\begin{tabular}{cccc}
\hline \multirow{2}{*}{ Field capacity \% } & \multicolumn{3}{c}{ Shoot length $(\mathbf{c m})$} \\
\cline { 2 - 4 } & C. dactylon & D. triflorum & C. trigonum \\
\hline 100 & $111.44^{\mathrm{a}} \pm 8.700$ & $35.40^{\mathrm{b}} \pm 5.985$ & $74.00^{\mathrm{a}} \pm 6.980$ \\
75 & $99.48^{\mathrm{a}} \pm 7.001$ & $34.16^{\mathrm{b}} \pm 4.701$ & $52.20^{\mathrm{b}} \pm 5.896$ \\
65 & $97.64^{\mathrm{a}} \pm 5.708$ & $34.06^{\mathrm{b}} \pm 3.491$ & $42.32^{\mathrm{b}} \pm 5.934$ \\
55 & $97.44^{\mathrm{a}} \pm 6.631$ & $32.96^{\mathrm{b}} \pm 4.004$ & $40.40^{\mathrm{b}} \pm 3.001$
\end{tabular}

Means in a column with the same letters are not significantly different at the 0.05 probability level.

\section{Root Growth Parameters}

Results indicate that the root fresh weight in $C$. dactylon was not significantly affected with induced drought conditions (Table 5). However, in D. triflorum and $C$. trigonum root fresh weight all the water deficit treatments were significantly low compared to the control. In $D$. triflorum root fresh weights were not significantly different among other treatments whereas in $C$. trigonum significantly lower values were recorded in $65 \%$ and $55 \%$ field capacity levels.

A similar trend was observed for root dry weights (Table 6). In C. dactylon root dry weights were not significantly affected with induced drought conditions (Table 6). A similar trend was observed in D. triflorum. In C. trigonum, compared to $100 \%$ and $75 \%$ field capacity levels, 55\% field capacity level recorded significantly low root dry weights.

Table 5. Root fresh weight (g) of grass species at different field capacity levels

\begin{tabular}{cccc}
\hline \multirow{2}{*}{ Field capacity \% } & \multicolumn{3}{c}{ Root fresh weight $(\mathrm{g})$} \\
\cline { 2 - 4 } & C. dactylon & D. triflorum & C. trigonum \\
\hline 100 & $3.168^{\mathrm{a}} \pm 0.941$ & $2.024^{\mathrm{a}} \pm 0.395$ & $1.998^{\mathrm{a}} \pm 0.231$ \\
75 & $3.132^{\mathrm{a}} \pm 0.989$ & $1.016^{\mathrm{b}} \pm 0.687$ & $0.928^{\mathrm{b}} \pm 0.290$ \\
65 & $2.624^{\mathrm{a}} \pm 0.641$ & $1.002^{\mathrm{b}} \pm 0.291$ & $0.572^{\mathrm{c}} \pm 0.093$ \\
55 & $1.996^{\mathrm{a}} \pm 0.091$ & $0.972^{\mathrm{b}} \pm 0.091$ & $0.428^{\mathrm{c}} \pm 0.079$ \\
\hline
\end{tabular}

Means in a column with the same letters are not significantly different at the 0.05 probability level. 
Table 6. Root dry weight (g) of grass species at different field capacity levels

\begin{tabular}{cccc}
\hline \multirow{2}{*}{ Field capacity \% } & \multicolumn{3}{c}{ Root dry weight $(\mathrm{g})$} \\
\cline { 2 - 4 } & C. dactylon & D. triflorum & C. trigonum \\
\hline 100 & $1.424^{\mathrm{a}} \pm 0.965$ & $0.744^{\mathrm{ab}} \pm 0.099$ & $0.652^{\mathrm{ab}} \pm 0.098$ \\
75 & $1.288^{\mathrm{a}} \pm 0.998$ & $0.420^{\mathrm{b}} \pm 0.062$ & $0.408^{\mathrm{b}} \pm 0.029$ \\
65 & $0.932^{\mathrm{a}} \pm 0.195$ & $0.408^{\mathrm{b}} \pm 0.075$ & $0.350^{\mathrm{bc}} \pm 0.031$ \\
55 & $0.720^{\mathrm{ab}} \pm 0.058$ & $0.400^{\mathrm{b}} \pm 0.031$ & $0.296^{\mathrm{c}} \pm 0.024$ \\
\hline
\end{tabular}

$\overline{\text { Means in a column with the same letters are not significantly different at the } 0.05}$ probability level.

Root lengths were not significantly affected in all the three species under different drought stress conditions (Table 7).

Table 7. Root length $(\mathrm{cm})$ of grass species at different field capacity levels

\begin{tabular}{cccc}
\hline \multirow{2}{*}{ Field capacity \% } & \multicolumn{3}{c}{ Root length $(\mathbf{c m})$} \\
\cline { 2 - 4 } & C. dactylon & D. triflorum & C. trigonum \\
\hline 100 & $43.96^{\mathrm{a}} \pm 6.978$ & $28.48^{\mathrm{a}} \pm 7.431$ & $21.76^{\mathrm{a}} \pm 5.381$ \\
75 & $43.60^{\mathrm{a}} \pm 7.001$ & $25.88^{\mathrm{a}} \pm 6.875$ & $21.52^{\mathrm{a}} \pm 6.000$ \\
65 & $36.12^{\mathrm{a}} \pm 5.471$ & $27.08^{\mathrm{a}} \pm 6.690$ & $22.44^{\mathrm{a}} \pm 5.041$ \\
55 & $36.16^{\mathrm{a}} \pm 6.891$ & $21.76^{\mathrm{a}} \pm 5.801$ & $21.40^{\mathrm{a}} \pm 4.650$ \\
\hline
\end{tabular}

Means in a column with the same letters are not significantly different at the 0.05 probability level.

\section{Lawn Quality Evaluation}

The visual quality of the ground covers was determined by the attributes colour of the foliage, leaf cover and overall appearance. Ranks for all the attributes were decreased with the increased water deficiency levels.

On the basis of colour, the highest visual quality ranks were recorded in $D$. triflorum followed by $C$. dactylon (Table 8). There was no effect of water stress on the colour in D. triflorum foliage. However, induced drought has an effect on the colour of the other two species. Leaf coverage also declined with the reduction of water level and the ranks for $75 \%$ field capacity levels were above the acceptable level for all the three species. In both D. triflorum and C. dactylon the ranks of $65 \%$ field capacity levels were above the acceptable level for overall appearance. However, in C. trigonum only $100 \%$ field capacity level was above the acceptable level for overall appearance. 
Table 8. Lawn quality acceptance ranks for different field capacity levels

\begin{tabular}{|c|c|c|c|c|c|c|c|c|c|c|c|c|c|}
\hline \multirow{3}{*}{ 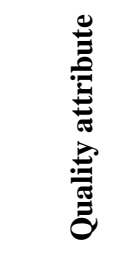 } & \multirow{3}{*}{ 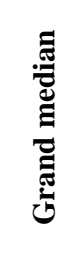 } & \multicolumn{12}{|c|}{ Ground cover species and respective field capacities } \\
\hline & & \multicolumn{4}{|c|}{ C. dactylon } & \multicolumn{4}{|c|}{ D. triflorum } & \multicolumn{4}{|c|}{ C. trigonum } \\
\hline & & $\begin{array}{l}\text { de } \\
\stackrel{\theta}{\theta}\end{array}$ & $\begin{array}{l}2 \\
i n\end{array}$ & $\begin{array}{l}8 \\
16\end{array}$ & $\begin{array}{l}s^{0} \\
\text { in }\end{array}$ & $\begin{array}{l}\text { so } \\
\stackrel{8}{0}\end{array}$ & $\begin{array}{l}a^{2} \\
12\end{array}$ & $\begin{array}{l}0 \\
10\end{array}$ & $\begin{array}{l}D^{0} \\
\text { in }\end{array}$ & $\begin{array}{l}\stackrel{0}{0} \\
\stackrel{\theta}{\theta}\end{array}$ & $\begin{array}{l}20 \\
i 2\end{array}$ & $\begin{array}{l}8 \\
i\end{array}$ & $\begin{array}{l}8 \\
\text { in }\end{array}$ \\
\hline Colour & 3.14 & 3.52 & 3.14 & 2.60 & 2.56 & 4.35 & 3.81 & 3.65 & 3.52 & 2.82 & 2.71 & 2.69 & 2.60 \\
\hline Leaf cover & 3.27 & 4.19 & 3.39 & 3.06 & 2.23 & 4.73 & 3.43 & 2.97 & 2.97 & 4.15 & 3.27 & 2.65 & 2.19 \\
\hline $\begin{array}{l}\text { Overall } \\
\text { appearance }\end{array}$ & 3.16 & 3.62 & 3.32 & 3.24 & 2.19 & 4.41 & 3.49 & 3.19 & 3.07 & 3.45 & 3.12 & 2.49 & 2.28 \\
\hline
\end{tabular}

\section{Discussion}

Ground covers are widely used in landscapes to fill spaces in residential gardens, sport fields and other public open spaces. Since fresh water resources for irrigation are becoming limited, identification of drought tolerant species will be of great value to landscape managers. To make the ground covers water stress tolerant, understanding plant responses to water-limited environments is of great importance. In landscaping, leaves and shoots play an important role in aesthetics where people can appreciate their appearance. Besides shoots and leaves, root growth is an important parameter for plant tolerance to drought stress as roots are the main engine for meeting transpirational demand and they play an important role in making water available to plants (Huang and Gao, 1999).

Cynodon dactylon (Poaceae) is a fine to robust stoloniferous perennial grass with a rhizome. According to Cook et al., (2005), it has been introduced to all tropical, subtropical and some temperate regions of the world. Desmodium triflorum (Fabaceae) is a small prostrate perennial legume with a woody tap root. Stems are strongly branched and frequently rooted at the nodes to form a mat. According to Cook et al., (2005), it occurs in the humid tropics and warmer subtropics and is well adapted to tropical and warm subtropical environments. Cyrtococcum trigonum (Poaceae) is a perennial, mat forming grass which produces roots from lower nodes. Compared to C. trigonum, the other two species are popular as ground covers in Sri Lanka.

Landscapes containing low water use ground cover plants are promising alternatives to conventional lawn grass-based landscapes and have the potential to significantly reduce overall landscape water use (Heflebower et al., 2005). The present study indicates that induced drought conditions had a significant inhibitory effect on shoot growth parameters. Though shoot fresh weights were not significantly different at $100 \%$ field capacity level in all the three species, shoot dry weights were significantly reduced in $D$. triflorum and $C$. trigonum. This indicates that shoot growth rate is high in $C$. dactylon under optimal water levels. In all the three 
species, fresh and dry weights were significantly reduced with induced drought but only in C. dactylon, compared to $75 \%$ and $65 \%$ field capacity levels at $55 \%$ field capacity level it was not significantly reduced. Therefore even-under $55 \%$ field capacity level shoot fresh and dry weights of $C$. dactylon was significantly high compared to the other two species. The induced drought conditions do not significantly affect the shoot length in $C$. dactylon and $D$. triflorum but affect $C$. trigonum. Hence, the induced drought levels have the least effect on shoot growth parameters of $C$. dactylon followed by $D$. triflorum. Root fresh and dry weights in $C$. dactylon were not significantly affected by induced drought conditions. However, root fresh weight was significantly reduced in D. triflorum but not the root dry weight. In $C$. trigonum both root fresh and dry weights were significantly reduced with induced drought. Hence, the induced drought levels have the least effect on root growth parameters of $C$. dactylon followed by $D$. triflorum. Therefore, in $C$. dactylon though induced drought has a negative effect on growth parameters even at $55 \%$ field capacity level, its performance is not significantly reduced compared to $75 \%$ field capacity level. In $C$. trigonum growth parameters were significantly reduced below $75 \%$ field capacity level. Hence, based on the overall result for growth parameters $C$. dactylon has better ability to cope with drought stress followed by $D$. triflorum.

With regard to the quality attributes, D. triflorum received best ranks for overall quality followed by $C$. dactylon. The reason could be leaf firing not being observed with induced drought conditions in $D$. triflorum even though it was observed in grass species. According to Carrow and Duncan (2003), leaf firing and loss of live green cover provides a good assessment of overall turfgrass drought resistance. In C. trigonum, $100 \%$ field capacity level was the only acceptable level which was severely affected by the water stress. In addition to $100 \%$ field capacity level, $75 \%$ and $65 \%$ field capacity levels in D. triflorum and $C$. dactylon received above average ranks for lawn appearance. Considering all above attributes, overall lawn quality in three species was affected with the progression of drought stress. While based on quality evaluation attributes, $C$. trigonum was the severely affected species compared to others.

The particular level of irrigation needed to maintain acceptable quality appears to vary among species (Wherley, 2011). Compared to $C$. trigonum, though physiologically $C$. dactylon and $D$. triflorum can tolerate a water stress of $55 \%$ field capacity level, overall appearance is reduced after $65 \%$ field capacity level. Hence $65 \%$ field capacity level can be considered as the acceptable irrigation deficit at which acceptable quality could be maintained in $C$. dactylon and $D$. triflorum. However, in C. trigonum, overall appearance is reduced below $100 \%$ field capacity level. Therefore, compared to other two species with $C$. trigonum, deficit irrigation is not recommended to be practiced as it could reduce the visual quality. 


\section{Conclusions}

Induced drought conditions had a significant inhibitory effect on growth parameters and overall lawn quality of the studied species and $65 \%$ field capacity level can be considered as the acceptable irrigation deficit for $C$. dactylon and $D$. triflorum whereas deficit irrigation is not recommended to practice with $C$. trigonum.

\section{References}

Bahrani, M. J., H. Bahrami and A. A. K. Haghighi (2010). "Effect of water stress on ten forage grasses native or introduced to Iran". Grassland Science, 56:1-5.

Carrow, R. N. and R. R. Duncan (2003). "Improving drought resistance and persistence in lawn-type tall fescue”. Crop Science, 43: 978-984.

Cook, B. G., B. C. Pengelly, S. D. Brown, J. L. Donnelly, D. A. Eagles, M. A. Franco, J. Hanson, B. F. Mullen, I. J. Partridge, M. Peters and R. Schultze-Kraft (2005). "Tropical forages: an interactive selection tool". CSIRO, DPI \& F (Qld), CIAT and ILRI, Brisbane, Australia.

Fry, J. D. and J. D. Butler (1989). "Responses of tall fescue and hard fescue to deficit irrigation”. Crop Science. 29: 1536-1541.

Fu, J., J. Fry and B. Huang (2004). "Minimum water requirements of four turf grasses in the transition zone". HortScience, 39: 1740-1744.

Fu, J., J. Fry, J. and B. Huang (2005). "Minimum water requirements of four lawn grasses in transition zone". HortScience, 39: 1740-1749.

Fu, J., J. Fry, J. and B. Huang (2007). "Tall fescue rooting as affected by deficit irrigation". HortScience, 42(3): 688-691.

Heflebower, R., T. Cerny-koenig, M. Waters and R. Ward (2005). "Water-wise plant recognition program”. Extension Journal, 43(1).

Huang, B. and H. Gao (1999). "Physiological responses of divers tall fescue cultivars to drought Stress". HortScience, 34: 897-901

Lin, K. H. R., C. C. Tsou, S. Y. Hwang, L. F. Chen and H. F. Lo (2006). "Paclobutrazol pretreatment enhanced flooding tolerance of sweet potato". Journal of Plant Physiology, 7: 750-760.

Milesi, C., A. Samanta, H. Hashimoto, K. K. Kumar, S. Ganguly, P. S. Thenkabail, A. N. Srivastava, R. R. Nemani and R. B. Myneni (2010). "Decadal variations in NDVI and food production in India". Remote Sensing, 2: 758-776.

Mortimore, M. (2009). Dryland Opportunities, IUCN, Gland, Switzerland. 
Nichols, R., A. Miehls, J. Baird, D. Jenerette and L. Allsman (2012). "Evaluation of turf grasses and a ground cover under drought and extreme deficit irrigation". Research report. University of California, Riverside and Turf grass and landscape foundation, Califonia.

Nudrat, A. A., M. Shahbaz and M. Ashraf (2008). "Nutrient acquisition in differentially adapted populations of Cynodon dactylon (L.) Pers and Cenchrus ciliaris under drought stress". Pakistan Journal of Botany, 40: 1433-1440.

Overpeck, J. and B. Udall (2010). “Dry times ahead”. Science. 328: 1642-1643.

Qian, Y. L. and M. C. Engelke (1999a). "Performance of five turf grasses under linear gradient Irrigation". HortScience, 34(5): 893-896.

Qian, Y. L. and M. C. Engelke (1999b). "Turf grass selection: Comparing three turf grasses for minimum irrigation requirements, drought resistance and long-term performance". Turf grass Trends, 8: 4-8.

Riaz, A., A. Younis, M. Hameed and S. Kiran (2010). "Morphological and biochemical responses of lawn grasses to water deficit conditions". Pakistan Journal of Botany, 42(5): 3441-3448.

Somasegaran, P. and H. J. Heben (1985). "Methods in legume - Rhizobium technology". Nitrogen Fixation in Tropical Agricultural Legumes and Microbiological Resources Center, University of Hawaii, 432-435.

UNEP. (1992). “World atlas of desertification”. London, Edward Arnold.

Wherley, B. (2011). "Turf grass growth, quality, and reflective heat load in response to deficit irrigation practices". In Evapotranspiration. Labedzki, L. (Ed.), 419-430. Available online: http://www.intechopen.com/books/evapotranspiration/turfgrassgrowth-quality-and-reflectiveheat-load-in-response-to-deficit-irrigation-practices. 